\begin{tabular}{l}
\hline OPEN O ACCESS Freely available online \\
http://www.banglajol.info/index.php/BJID/index \\
Opinion \\
Bangladesh Journal of Infectious Diseases \\
April 2020, Volume 7, Number Suppl_1, Page S61-S62 \\
ISSN (Online) 2411-670X \\
ISSN (Print) 2411-4820 \\
DOI: https://doi.org/10.3329/bjid.v7i0.46806
\end{tabular}

\title{
Herd Immunity of Covid19- Goal or Outcomes?
}

\author{
Reaz Fatema Popy \\ GP Registrar, St Helens and Knowsley Teaching Hospitals NHS Trust, United Kingdom
}

[Received: 26 March 2020; Accepted: 2 April 2020; Published: 25 April 2020]

\begin{abstract}
Herd immunity is the indirect protection from a contagious infectious disease. This happens when a population is immune either through vaccination or immunity developed through previous infection. This means that even people who aren't vaccinated, or in whom the vaccine doesn't trigger immunity, are protected because people around them who are immune can act as buffers between them and an infected person. Once herd immunity has been established for a while, and the ability of the disease to spread is hindered, the disease can eventually be eliminated.
\end{abstract}

It has been attempted to predict the cumulative number of cases of Coronavirus Disease 2019 (COVID-19) in China ${ }^{1}$. However, since then, the epidemic has rapidly evolved into a pandemic affecting many countries worldwide. Serious debates have been raised considering the spread of this disease, particularly by European countries, such as Italy, Spain, Germany, France and the UK. These includes from closing schools and universities to locking down entire cities and countries. There is an alternative strategy which would be to allow the causal virus (SARS-CoV-2) to spread to increase the population herd immunity; however, at the same time protecting the elderly and those with multiple comorbidities, who are the most vulnerable to this virus $^{3}$.

\section{Challenges in Creating Herd Immunity}

During a pandemic of an infectious disease, a large portion of the population need to be infected to attain herd immunity. In case of measles it is highly contagious and one person with measles can infect up to 18 other people. This means that around $95.0 \%$ of people need to be immune in order for the wider group to have herd immunity. The new SARS CoV2 has a lower infection rate than measles and each infected person can pass it on to two or three new people, on average. This means that herd immunity should be achieved when around $60.0 \%$ of the population becomes immune to COVID-19.

However, natural herd immunity can be achieved through infection rather than vaccination. It can be challenging though, as there would be a very high rate of serious illness and death; furthermore, there will be an overwhelmed health system beyond their surge capacity, even in high-income countries. Therefore, herd immunity is generally pursued through vaccination programmes. Even when vaccines are available, it is not always possible to achieve herd immunity for very long. Some viruses, such as seasonal flu, mutate frequently, evading the body's immune response. So immunity doesn't always last forever, which is why the flu shot is necessary every single year.

\section{Risks of Herd Immunity}

There are several risks of herd immunity. While mass vaccination is an important tool and has been highly successful in inducing herd immunity for many diseases., the overall immunity level can get compromised and herd immunity can be lost because of some anti-vaccine ideologies. For example, when herd immunity is well established, however, some people choose to move everywhere, essentially benefitting from everyone else getting vaccinated, while abstaining from vaccination either because they choose not to or are actively anti-vaccination. When a population has too many of these free riders, the overall immunity level is bound to get compromised, putting everyone at risk. 
Currently, there is a huge impact on health systems in wealthier countries by COVID-19 virus, in terms of insufficiency of much needed ITU/ICU facilities and trained health professionals to tackle this unprecedented situation. However, in countries with weak health systems it could be catastrophic. This Covid19 virus has infected without any restriction and created a critical situation in areas with poor hygiene and infection control practices among health workers i.e. in areas of infection control supplies, surveillance and laboratory testing facilities.

There are basically three ways to stop the Covid-19 disease for good. One involves extraordinary restrictions on free movement and assembly, as well as aggressive testing, to interrupt its transmission entirely. That may be impossible now that the virus is in over 100 countries. The second is a vaccine that could protect everyone. The coronavirus vaccine has been developed in under three months' time by a team at Oxford University. Sarah Gilbert, professor of vaccinology at the Jenner institute, led the research, who has high degree of confidence in the vaccine and the first human trial has just begun in Oxford. However, it might take a while to confirm the effectivity of the newly developed vaccine. A third is potentially effective herd immunity. If the virus keeps spreading, a large number of people will be infected and eventually will become immune and the outbreak will be compelled to fizzle out on its own as the germ would find it harder and harder to find a susceptible host. This phenomenon is known as herd immunity. Wide, unstoppable spread of the coronavirus is exactly an outcome; however, experts are modeling in their worst-case scenarios and have told that this covid 19 virus can end up after infecting about $60.0 \%$ of the world's population, even within the year ${ }^{4}$.

The herd immunity idea has created a new dimension in UK when the country's official strategy is to let the disease run its own course. The chief science adviser to the UK government, Patrick Vallance, said the country needed to "build up some kind of herd immunity so more people are immune to this disease and we reduce the transmission."

\section{Conclusion}

The strategy of herd immunity in right away would be disastrous and ethically questionable, which has been found in the newest models. That's because so many people will become severely ill and a sudden boom in sick people needing hospital or ICU care will overwhelm hospitals. Slowing it down of virus would mean health systems could be spared and lives saved, but ultimately the result could be the same. That is, even if the pandemic is drawn out over time, it may still take herd immunity to bring it to an end. As Matt Hancock, the UK Secretary for health and social care, clarified after criticism of the UK government: "Herd immunity is not our goal or policy. It's a scientific concept."

\section{References}

1. Fu X, Ying Q, Zeng T, Long T, Wang Y. Simulating and forecasting the cumulative confirmed cases of SARS-CoV-2 in China by Boltzmann function-based regression analyses. J Infect. 2020 pii: S0163-4453(20)30098-0

2. Coronavirus: some scientists say UK virus strategy is `risking lives'.https://www.bbc.co.uk/news/science-environment51892402. Accessed 14 March2020

3. https://www.gavi.org/vaccineswork/what-herdimmunityhttps://www.gavi.org/vaccineswork/what-herdimmunity

4. https://www.gavi.org/news/media-room/gavi-board-callsbold-engagement-respond-covid-19

[Bangladesh Journal of Infectious Diseases, April 2020;7(suppl_1):S61-S62]

Correspondence: Dr. Reaz Fatema Popy, GP Registrar, St Helens and Knowsley Teaching Hospitals NHS Trust, United Kingdom; Email: dr_reaz_fatema@hotmail.com; Cell no.: $+447572106981$

Conflict of Interest: Author has declared no competing interests.

How to cite this article: Fatema R. Herd Immunity of Covid19Goal or Outcomes? Bangladesh J Infect Dis 2020;7(suppl_1):S61-S62

Copyright: (2020. Fatema. Published by Bangladesh Journal of Infectious Diseases. This article is published under the Creative Commons CC BY-NC License (https://creativecommons.org/licenses/by-nc/4.0/). This license permits use, distribution and reproduction in any medium, provided the original work is properly cited, and is not used for commercial purposes 